\title{
A psicanálise na alfabetização
}

\section{The psychoanalysis in alphabetization}

\section{La psychanalyse dans l' alphabétisation}

Sonia BORGES

\section{RESUMO}

No campo dos estudos sobre a escrita, o reconhecimento da inscrição do processo de sua aquisição no campo da linguística e da psicanálise abre perspectivas para que as relações oralidade/escrita sejam consideradas segundo um novo prisma. Ao pesquisador fica aberta a possibilidade de descrever as transformações gráfico-textuais na escrita da criança, até então desconsiderada pelas teorias da alfabetização, enquanto efeito de um funcionamento linguístico-discursivo que as inclue. Neste funcionamento, linguagem oral e linguagem escrita emergem numa relação de mútua constituição.

Palavras-chave: aquisição da escrita, linguística, psicanálise.

\section{ABSTRACT}

In writing studies field, the recognition of acquisition process inside linguistics and psychoanalysis area opens perspectives to orality/ writing relations are considered according to a new point of view. Researcher has the possibility to describe textual and graphic transformations in children's writing, until now not taken into consideration by alphabetization theories, as an effect of a discursive-linguistic functioning that includes them. In this functioning, oral and written communication emerge in a mutual and constitution relation.

Index terms: writing acquisition, linguistics, psychoanalysis.

\section{RESUME}

Dans le champ des études sur l'écriture, la reconnaissance de l'enregistrement du processus de son acquisition dans le champ de la linguistique et de la psychanalyse ouvre des perspectives pour que les relations oralité/écrite soient considérées selon un nouveau prisme. Au chercheur est ouverte la possibilité de décrire les transformations de 
graphie et textuelles dans l'écriture de l'enfant, jusqu'à alors déconsidérée par les théories de l'alphabétisation, comme effet d'un fonctionnement linguístico-discursive inclusif. En ce fonctionnement, la langue verbale et la langue écrite émergent dans une relation de mutuelle constitution.

Mots clés: acquisition de l'écriture, linguistique, psychanalyse.

\section{Introdução}

Meu objetivo, neste trabalho, é mostrar que a crítica ao fonocentrismo, que marca, de um modo geral, os estudos sobre a linguagem, é essencial para o desenvolvimento dos estudos sobre a escrita. A filosofia e a linguística sempre tiveram como objeto privilegiado a modalidade oral da língua. Esta primazia da oralidade, que coloca a escrita em um lugar de exterioridade/secundariedade, não pode ser considerada inocente. Seu caráter ideológico é denunciado por Derrida (1967) e Foucault (1987) ao mostrarem que esta postura carrega o peso de toda uma tradição filosófica logofonocêntrica, que se ordena em torno das noções de substância e de representação. Para Derrida (1967), é necessário retornar ao Curso de Linguística Geral, às páginas consagradas $\square$ ao valor do signo linguístico onde à escrita, reabilitada, é atribuído um lugar entre outros sistemas, ao lado do alfabeto dos surdos-mudos, dos ritos simbólicos, das formas de polidez, dos signos militares, etc. $\square$ (Cf. SAUSSURE, 1974, p. 25). A desconstrução da concepção representacionista da escrita exige o retorno a Saussure, porque implica o reconhecimento da tríade língua/fala/escrita. Esta, por sua vez, possibilita a compreensão de que a distinção entre fala e escrita não pode ser reduzida à diferença entre as suas substâncias de expressão. 


\section{Pesquisa: desconstrução da visão representacionista}

Na pesquisa que vimos desenvolvendo, os dados já obtidos têm apontado para a relevância da desconstrução da visão representacionista quando se trata do ensino da língua escrita. Nesta direção, desenvolvemos experiência alternativa de alfabetização, e é possível observar, mesmo nas produções bem iniciais das crianças, características gráfico-textuais reveladoras de um funcionamento operado pelo que é da ordem do sistema de imagens gráficas que suporta a língua escrita. Nesta experiência, as crianças são colocadas diariamente em situações de leitura e de escrita de textos. É nossa hipótese que a intensificação de suas relações com textos possibilita a sua "entrada" na escrita como efeito não de ensino, mas do próprio funcionamento da linguagem, que as captura. Neste caso, a escrita não é mais concebida, de forma cômoda como representação, materialização gráfica da sua fala, mas estabeleceria com ela uma relação de constituição mútua num plano em que estariam em jogo a tríade oralidade-escrita-língua.

As várias teorias da alfabetização, todas elas fundamentadas na Psicologia, convergem quanto a um ponto: têm a noção de representação como eixo do seu corpo teórico. Ferreiro e Teberosky (1999) falam da alfabetização como uma construção da representação conceitual da base alfabética. Vygotsky (1988) diz que a criança constrói a escrita como representação da fala para, mais tarde, reconstruí-la como representação no mundo. Investigadores do campo da psicolinguística têm em comum uma visão pragmático-funcionalista da aquisição da escrita, também manifestam uma posição representacionista. Guardadas as diferenças, suas concepções se fundamentam na idéia de que o processo de alfabetização é guiado por processos cognitivos, que são, por sua vez, determinados por representações sobre os usos sociais da escrita. Em qualquer uma dessas 
teorias - porque marcadas pela compreensão idealista-representacionista clássica da linguagem - não se reconhece que a alfabetização é um fato linguístico. Em outras palavras, um processo que ocorre no campo da linguagem, pois a natureza particular do objeto língua escrita implica a sobredeterminação de sua aquisição pelo que Saussure (1976) chamou de $a$ ordem própria da língua.

O deslocamento teórico que nos levou a essas hipóteses, e tornou possível a realização desse trabalho, indica a nossa filiação às elaborações de Cláudia Lemos (1992)- o "interacionismo dialógico" - no campo dos estudos da aquisição de linguagem. De acordo com tais estudos, inspirados no estruturalismo línguístico, particularmente em Jakobson (s.d) e Saussure (1976), e em Lacan $(1986,1988)$, o outro da criança, o outro-tesouro-designificantes que sobre-determina a aquisição da linguagem, é o funcionamento linguístico-discursivo (Cf. LEMOS, 1992).

No texto Los processos metafóricos e metonímicos como mecanismos de câmbio (LEMOS, 1992), esta pesquisadora coloca em questão a impossibilidade de representação da linguagem e aponta as noções de língua, signo, significante, metáfora e metonímia, ou seja, aponta o funcionamento da linguagem, como lugar privilegiado para a descrição da fala da criança. É exatamente o reconhecimento da resistência da fala da criança a uma descrição representacionista (que implica a sua presença, enquanto sujeito, na "origem" de suas representações sobre a linguagem) que vem possibilitando a Lemos reconhecer que sob a aparente indeterminação e a grande heterogeneidade de forma que comparecem na fala e na escrita inicial está a sua "dependência dialógica" (cf. LEMOS, 1987). 
Isto significa que o universo discursivo em que criança está inserida é determinante de sua fala e de sua escrita, e por isso mesmo, condição de sua interpretação.

No campo dos estudos sobre a escrita, o reconhecimento da inscrição do processo de sua aquisição no campo do linguístico abre perspectivas para que as relações oralidade/escrita, nesse processo, sejam consideradas segundo um novo prisma. A inclusão da noção de língua abre uma brecha na clausura da relação dual oralidade-escrita em que a concepção representacionista as colocou. Ao pesquisador fica, então, aberta a possibilidade de descrever as transformações gráfico-textuais na escrita da criança, até então desconsiderada pelas teorias da alfabetização, enquanto efeito do funcionamento linguístico-discursivo que as incluem. Neste funcionamento, linguagem oral e linguagem escrita emergem numa relação de mútua constituição que se deixa perceber no jogo metaforonímico de unidades linguísticas de diversas naturezas e extensões.

A natureza da letra, ou seja, dos aspectos gráficos da escrita e o seu papel no processo de aquisição da escrita talvez possam ser melhor compreendidos se buscarmos em outra escrita, que não a alfabética, elementos de reflexão. Tomemos para isso a escrita chinesa.

Na Gramatologia (1973), Derrida diz que o arrombamento da posição logofonocêntrica foi anunciado antes pelo lado da literatura e da escritura poética, que da Filosofia:

Este é o sentido dos trabalhos de Fenollosa, cuja influência sobre Ezra Pound e sua poética, é sabida: esta poética irredutivelmente gráfica era, como a de Mallarmé, a primeira ruptura da mais profunda tradição ocidental. A fascinação que o ideograma chinês exercia sobre a escritura de Pound adquire 
assim toda a sua significação historial (DERRIDA, 1973, p. 116).

Haroldo Campos, em seu belo artigo, Ideograma, Anagrama, Diagrama, uma leitura de Fenollosa (1994), conta que o poeta era apaixonado pela arte e pela poesia chinesa. Ele estudou em Harvard, e foi convidado para lecionar Filosofia no Japão, onde se dedicou, ao longo de toda a sua vida, a estudar o caráter plástico daquela poesia, ou seja, as relações entre o sentido poético e a configuração gráfica.

Fenollosa deixou como herdeiro cultural Ezra Pound, que, conforme Campos, tornou-se tradutor-inventor da poesia chinesa.

Em suas investigações, Fenollosa procurou perceber na análise intrínseca dos caracteres ideográficos, as fontes de prazer estético que os textos da poesia sino-japonesa proporcionam. Se Jakobson e Saussure se dedicaram à pesquisa do jogo fônico no verso, ele se entregou a um trabalho árduo e longo que o levou a poder reconhecer

(....) na poesia escrita chinesa, em nível grafemático, portanto, os harmônicos (overtones) vibrando diante do olho e "colorindo" todos os planos semânticos, à maneira de uma "dominante" (CAMPOS, 1994, p. 44).

Segundo Jakobson,

(....) pode-se definir o dominante como o centro de enfoque de um trabalho artístico: ele regulamenta, determina e transforma os seus outros componentes. $\mathrm{O}$ dominante garante a integridade da estrutura. (....) $\mathrm{Na}$ atualidade (...) a entonação passa a ser o 'dominante do verso' (JAKOBSON, s.d., p. 485).

Como mostra Fenollosa, os ideogramas compõem-se em cadeias para produzir sentidos impossíveis a uma unidade isolada. $\mathrm{O}$ processo 
ideogramático de compor, segundo descreve, $\square$ é equiparado ao da construção da metáfora: o uso de imagens materiais para sugerir relações imateriais $\square$ (JAKOBSON, s.d., p. 56). O que se pode perceber na Figura 1:

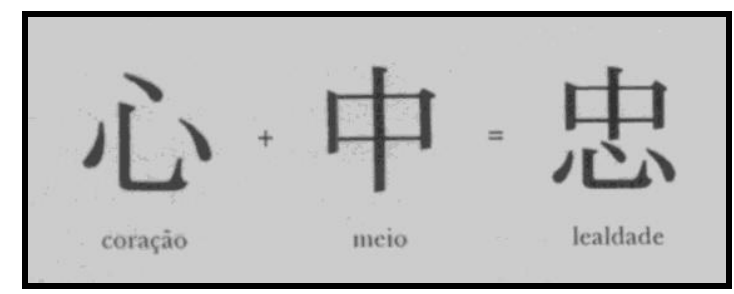

Figura 1

Pode-se ver que o pictograma sol se redistribuiu, se repete, por todos os signos construtivos do verso, $\square$ incidindo no de erguer e introjetando-se no de leste, como se um único grafemático regesse, com suas figuras em mutação, toda a cadeia fílmica da frase $\square$ (CAMPOS, 1994, p. 56) (Figura 2).

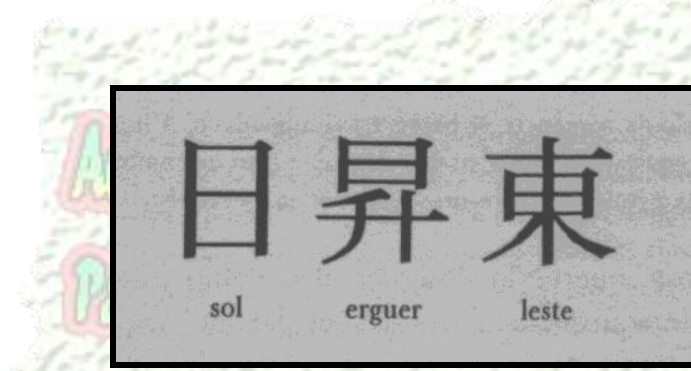

Figura 2

Parece-nos interessante, também a partir do artigo de Campos, citar um comentário de François Cheng, chefe do Centro de Linguística da Chinesa da École Pratique des Hautes Études, de Paris:

Mais do que simples suportes de sons, os ideogramas se impõem com todo o peso de sua presença física. Signos-presença e não signos-utensílios, eles chamam a atenção por sua força emblemática e pelo ritmo gestual que comportam. Em virtude de sua escrita, os chineses têm a impressão de apreender o universo através dos traços essenciais cujas combinações revelariam as leis dinâmica da transformação. Não é por acaso que na China a caligrafia que exalta a beleza visual dos caracteres, 
tornou-se uma arte maior (In: CAMPOS, 1994, p. $59)$.

No exemplo a seguir, sente-se a irradiação e contágio recíproco entre formas que se repetem com diferenças. Contemplando os caracteres na sua ordem, tem-se, com efeito, a impressão de se assistir ao processo de desenvolvimento de uma árvore. (Figura 3).

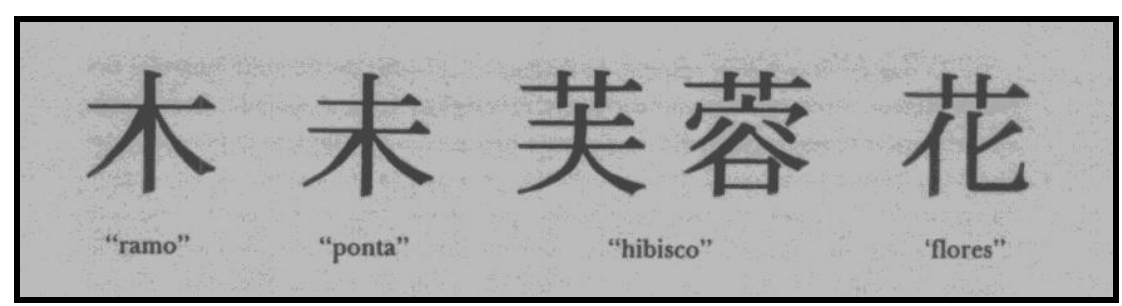

Figura 3

Derrida (1973) salienta que o modelo chinês funciona como um interruptor do logocentrismo ocidental, uma vez que é na pauta visual que reconhece a função poética. Livre do fonocentrismo, da posição secundária de representação da fala, a escrita chinesa pode significar no nível gráfico.

\section{A escrita de Palloma e algumas considerações necessárias}

Vejamos o que isto tem a ver com a escrita das crianças. Foi possível observar na escrita de Palloma que, de certo modo, nela também ocorre irradiação e contágio recíproco entre estrutura..

Na Figura 4, produção de Palloma, bem do início do ano, as letras estruturam-se em pseudo-palavras, que mantêm urna certa regularidade, particularmente, a partir de outra palavra (marca?) que veio do campo do outro: da palavra alna (aluna), que faz parte do cabeçalho que mostrar: a professora escreveu na lousa. Esta palavra repete-se compondo estruturas diferentes ao longo de quase todo o texto. É possível percebê-la sob as modificações. Trata-se da aparição do mesmo sob a figura de um outro, ou 
com outro semblante, um jogo com as diferenças. Ou da "diferência", como diz Derrida (1973), já que não se trata apenas de um trabalho com oposições, mas do funcionamento da língua, em que não há marcações prévias.

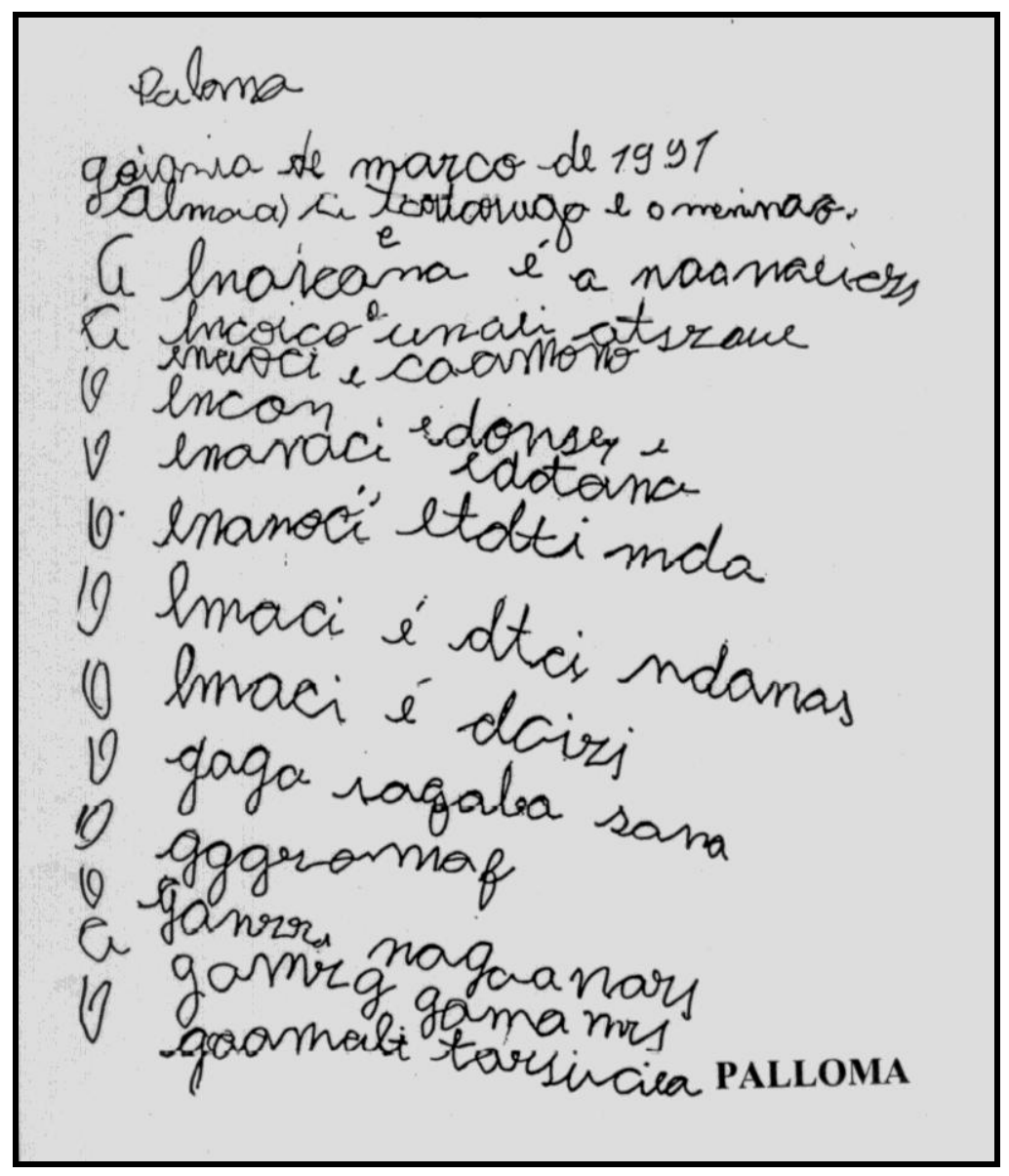

Figura 4

Esta composição visual que se inscreve - ou que se escreve - no texto da criança é também determinada pelo jogo entre os "espaços em branco" e os "espaços plenos" das palavras. Pode-se dizer que o "real da língua" comparece nos textos da criança nessas "metáforas de estruturas", produzidas pelo jogo de associações e combinações diferenciais de unidades que já são da língua constituída. 
Admitir a língua como um sistema não suturável - ou não representável - que existe para além do sujeito, não faz dela algo que não possa ser descrito. Ao funcionamento inconsciente da língua cabe subtrair as unidades linguísticas às leis do acaso. Essa sistematicidade singular que nelas se inscreve, responsável pelo estranhamento que causam ou pela ambiguidade que apresentam, é efeito do real da língua, que excede o nível gráfico e o fonológico da alfabetização. Levar em consideração a língua impede que esses níveis sejam objetivados, condição que seria necessária para que fossem considerados em uma relação dual de representação.

Observemos, na Figura 5, que as associações entre as letras não são livres. Estão alienadas ao Outro, aqui considerado como o funcionamento linguístico discursivo em que a criança está inserida. Isto pode ser percebido se tomarmos não esse texto isolado, mas, pelo menos mais a Figura 4, que o antecede, como unidade de análise. O papel do Outro, na constituição da escrita da criança, não se limita ao de provedor de unidades que se acrescentariam como unidades isoladas às que já são do seu domínio. Seus efeitos são de promoção de categorização de unidades e, simultaneamente, de constituição de estruturas.

A exposição a novos textos inscrevem novas letras e novas combinatórias de letras no texto de Palloma. Entretanto, isso importa menos que a "significância" que, pode-se também observar, tomam as letras ou as combinatórias de letras, retroativamente, como efeito dessa inscrição.

Observemos o fragmento, $\mathbf{O}$ imaci é dtci ndama s, que aparece na Figura 5. Pode-se ver que é efeito de uma certa reorganização, ou seja, da ressignificação dos "encadeamentos de letras" presentes na produção da 
figura 4. Observe-se, por exemplo, o encadeamento E lomci é d dmctima, que pode ser encontrado lá..

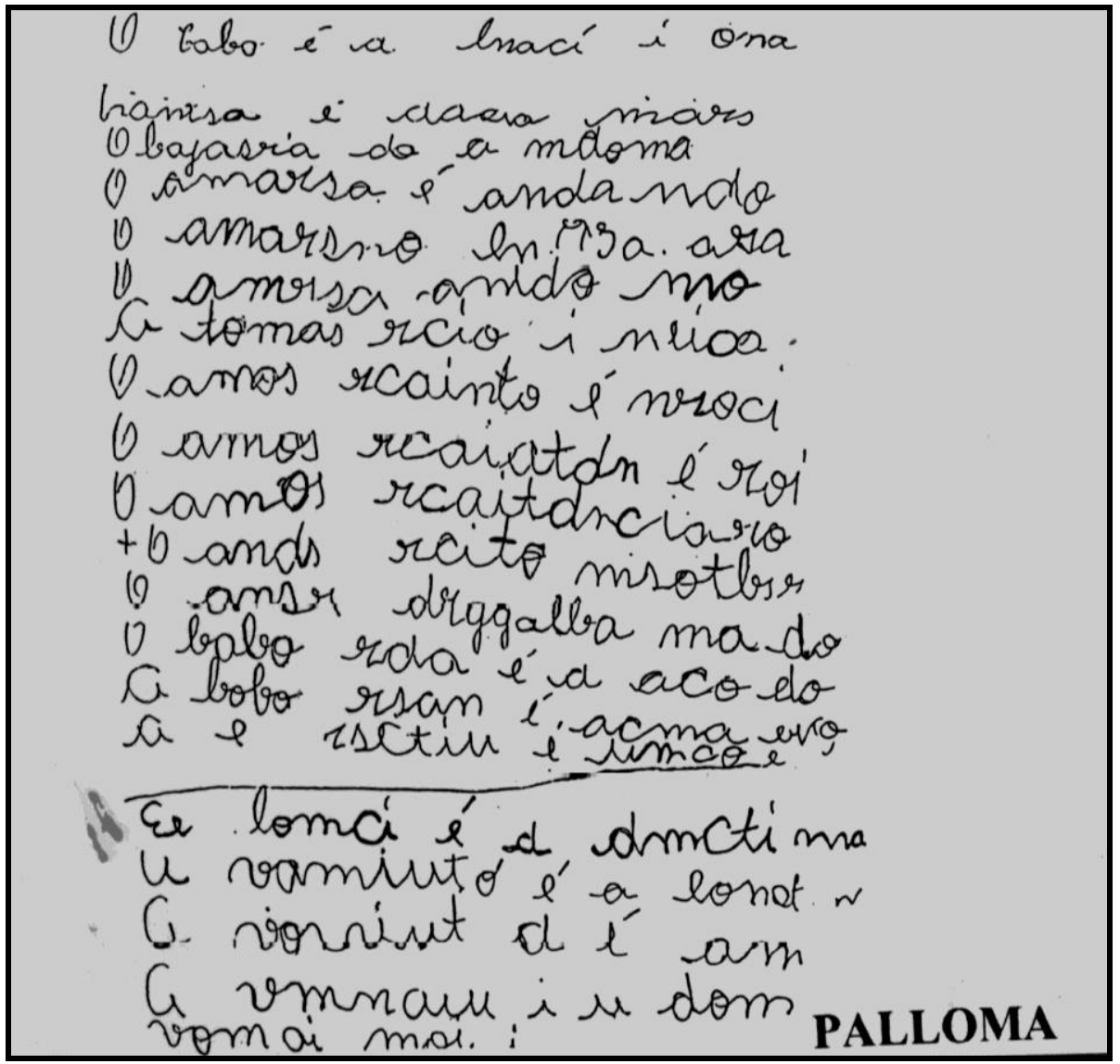

Figura 5

Nesse processo de ressignificação essas unidades são diferenciadas; emergem suas semelhanças e dissemelhança pelo fato de serem colocadas em relação. Pode-se dizer também, que já assumem uma posição estrutural. Não ainda as que virão a ter no só depois, quando assumirem um valor no conjunto das unidades de um discurso concreto. A categoria e a posição assumidas agora são virtuais, possibilitam as que hão de vir.

As produções até aqui apresentadas são representações da linguagem, mas no sentido psicanalítico do termo. Representações que, sob 
a pressão do imaginário, apresentam formas aparentemente descosidas umas das outras. E pouco a pouco que irão emergindo como cadeias cujas características serão da língua portuguesa constituída. Mas, note-se, a ordem que presidirá essa emergência vem do Outro, de fora, para retomarmos a expressão de Freud.

\section{Referências bibliográficas}

CAMPOS, H. (1994). Ideograma, anagrama, diagrama, uma leitura de Fenollosa. São Paulo: Editora USP.

DERRIDA, J. (1973). Gramatologia. São Paulo: Perspectiva.

FERREIRO, Emília; TEBEROSKY, Ana (1999). Psicogênese da língua escrita. Porto Alegre: Artes Médicas.

FOUCAULT M. (1987). As palavras e as coisas. São Paulo: Martins Fontes.

JAKOBSON R. (s.d.) Dois aspetos da linguagem e dois tipos de afasia. In: Linguagem e comunicação. São Paulo: Cultrix.

LACAN, J. (1986). Livro 1: Os escritos técnicos de Freud. Rio de Janeiro: Jorge Zahar Editor.

Editor. . (1988). Livro 3: as psicoses. Rio de Janeiro: Jorge Zahar

LEMOS, C. (1992). Os processos metafóricos e metonímico com mecanismos de mudança. Substratum. Porto Alegre: Artes Médicas.

SAUSSURE F. (1976). Curso de linguística geral. São Paulo: Cultrix.

VYGOTSKY, L. S. (1988). A formação social da mente. São Paulo: Martins Fontes. 


\section{Autora:}

\section{Sonia Borges}

Professora do Doutorado em "Psicanálise, Saúde e Sociedade", da Universidade Veiga de Almeida;

Psicanalista da Escola de Psicanálise do Campo Lacaniano

Contato: sxborges@uol.com.br

\section{Como citar este artigo:}

BORGES, Sonia. A psicanálise na alfabetização. Revista ACOALFAplp: Acolhendo a Alfabetização nos Países de Língua portuguesa, São Paulo, ano 5, n. 9, 2010/ 2011. Disponível em: <http://www.acoalfaplp.net>. Publicado em: setembro de 2010 - março de 2011.

Recebido em fevereiro de 2010. Aprovado em março de 2010.

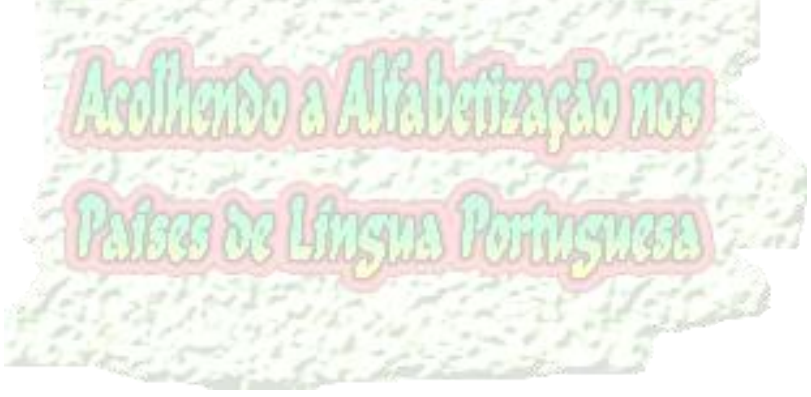

